\title{
KEHAOSADE NIMETUSTEST LÄÄNEMERESOOME KEELEATLASES ${ }^{1}$
}

\author{
HELMI NEETAR
}

\begin{abstract}
Annotatsioon: Artiklis vaadeldakse seitsme kehaosa (igemed, ninasõõre, oimukoht, pealagi, silmalaug, sääremari, selgroog) nimetusi. Keeleatlases käsitletakse neist igaüht eraldi, siinses artiklis tuuakse välja vaid üldisem: häälikuline ja tuletuslik varieerumine, levilad, semantiline külg, oma- ja laensõnad, nimeandmismotiivid. Viimastest on esikohal visuaalne külg (väliskuju, asukoht), seejärel funktsioon või muu.
\end{abstract}

Võtmesõnad: häälikuline ja tuletuslik varieerumine, levilad, semantiline külg, oma- ja laensõnad, nimeandmismotiivid

\section{1. Üldist}

Soome, Eesti ja Karjala keeleteadlaste ühistöö - läänemeresoome keeleatlas (Atlas Linguarum Fennicarum, ALFE) - on nüüdseks kolmeosalisena ilmunud (2004-2010). Selle 2. osas (ALFE II: 358-387) käsitletakse inimese anatoomiatki - kokku seitsme kehaosa nimetusi. Silmas on peetud seda, et tuleksid välja seosed ja erinevused läänemeresoome keelte või keelerühmade vahel. Arvestatud on ka häälikuloolisi seiku. Keeleaines saadi murdearhiivist (põhiliselt soome ja eesti keel), trükiallikaist (sõnaraamatud jms) ning seda koguti välitöödel (eeskätt karjala ja vepsa keel).

Kehaosad ise on järgmised: pea osad (igemed, ninasõõre, oimukoht, silmalaug, pealagi), sääremari, selgroog. Keelekaartidel esitatut selgitavad ja täiendavad kommentaarid. Siin antakse sõna(de) täpsem foneetiline kuju, vajaduse korral ka muud tähendused, etümoloogia, nimeandmismotiivid, vähe levinud sünonüümid (mida kaardil pole), kirjandusviited. Vaid kahel korral on tehtud eraldi motiivikaardid, nimelt oimukoha (ALFE II: 360) ja sääremarja kohta (ALFE II: 367).

Artikli aluseks on fennougristide 10. kongressil (Joškar-Ola, 2005) peetud ettekanne. Uurimistööd on rahastanud ETFi grant 7717. 
Atlases vaadeldakse nimetusi iga kehaosa kohta eraldi. Vaja oleks ka kokkuvõtlikku käsitlust, sest tähelepanu ja esiletõstu väärivad needki seigad, mis kõikide nimetuste puhul on ühised. Praegu pole mõttekas detailselt korrata juba atlases toodut, sest sellele saab viidata. Seetõttu esitatakse allpool üldisemaid tähelepanekuid. Vaadeldakse sõnade häälikulist ja tuletuslikku varieerumist, levilaid, semantilist külge, oma- ja laensõnade esinemust. Pikemalt peatutakse nimeandmismotiividel, kui need on läbinähtavad. Esitusviisi on tugevasti lihtsustatud, st et peaaegu on loobutud transkriptsioonist, enamasti ka häälikuvariantidest ja väga täpseist levikuandmeist. Artiklis kasutatakse üldistatud sõnakujusid (atlase märksõnu), mida vajaduse korral on siiski täpsustatud. Keeleaines pärineb atlase andmebaasist, mõnevõrra on lisainfot hangitud asjakohase keele sõnaraamatuist. Soomekeelsed tähendused on tõlgitud eesti keelde.

\section{Häälikuline ja tuletuslik varieerumine}

Siinkohal pole kõne all tavalised (enam-vähem ootuspärased) häälikulised erinevused. Allpool käsitletakse - kehaosade kaupa - neid nimetusi, kus varieerumine toimub kas läänemeresoome keelte eri rühmades või sama keele sees.

2.1. Igemed. Nimetuses võivad varieeruda nii konsonandid kui ka järgsilpide vokaalid, lisaks on keeliti (murdeti) toimunud mitut laadi eriarenguid (täpsemalt ALFE II: 354-357). Praegune esinemus (V = vokaal): $i k \mathrm{Vn}$ - (sm, krj, lü, vps, is), ikVm- (vdj, e, lv; harva krj, is). Karjala Paatene murraku $m$ on ilmselt mõjutatud in : ime-noomeneist, isuri Alam-Luuga oma aga eesti keelest. Üldiselt on peetud algupärasemaks $n$-tüve (SKES; SSA; Hahmo 1994: 31), kuid Viitso (1993) ei pea seda õigeks (vt ka 5.2). Eesti keeles käibivad harilikult igemed, kahes murrakus (Khk, Emm) on $g$ asemel sekundaarne $d$ (EEW). Vokaalidest on teises silbis enamasti $e$, harvemini $i$ (vps; eP (Saa) igimed; kohati eL igi-) või $\ddot{a}$ (sm ikäneet). Liivi 2. silbi vokaali saab sisekao tõttu üksnes oletada: $i$ 'gmõd. Vepsas on 3. silbis $e>o($ igino $(h o) d)$, lõunaeesti murretes kohati $e$ asemel $a / \ddot{a}$ (pl igima, igimä', igimadsõ ').

Kuivõrd varieeruvad eesti keeles (eriti lõunaeesti murretes) ainsuse nimetava kujud, nähtub asjakohaselt kaardilt ja selgub kommentaarist (ALFE II: 356-357). Tavaline on ige, harva ide (Khk, Emm). Obliikva- 
käändeist on lisandunud $m$ : igem (kohati eP, eL), idem (Emm). Vokaal $i$ on 2. silpi tulnud tõenäoliselt in : ime-tuletistest: eP (Saa) igi, eL igim, ikim, igi (Plv), igiman (Lei).

2.2. Oimukoht. Nimetustest varieerub kõige rohkem ohin-sõnapere (täpsemalt ALFE II: 359, 361-362). Harilikult on 2. silbis $i$, kuid esinevad muudki vokaalid. Ühtlasi on toimunud mitmesugused eriarengud ja käibivad erinevad tuletussufiksid: sm ohim(m)o, ohime, ohin : ohime/ohimma, ohin/paikka; ohalma, oha(l)mus, oha(v)us; ohelmus; oh(V)vainen $(\mathrm{V}=$ $u / o$ ). Karjala keeles märgib see sõnapere harva oimukohta: ohimo, ohima, ohavus, ohavoine (vt ka 4.1). Vadja keelest on vaid Setälä kirjapanek: Mati pl õhaassõt $(o>\tilde{o})$. Põhjaeesti murretestki leidub paar teadet: Rak pl ohemused, Vai oheme/koht.

2.3. Ninasõõre. Käibib kaks suuremat rühma (täpsemalt ALFE II: 378-379, 391-392). Sierain-sõnaperes varieeruvad in : ime-tuletised nii häälikuliselt kui ka muuteviisilt, olles mõnikord mugandunud teiste tuletustüüpidega: sm sierain (kohati sieraim), krj sierain. Kirderannikumurdes oli vanemal põlvkonnal 1. silbis ie (Kuu sieram, Vai pl sieramed), nooremal põlvkonnal ueloe (Vai suer(u)me, pl soermed). Sellesse sõnaperre kuuluvad veel vdj pl sõorrmõt, seermet, ka sõõramõt (XIX sajandi Iõpu kirjapanek); vps särm/serm (pikk vokaal lühenenud, $m$ üldistunud sisekaolisest genitiivivormist).

Eriti mitmekesine on esinemus eesti keeles: eP sõ̃̃re : sõorme (harilik), sõ̃ormas (Mär); eL sõ̃re (Nõo), sõ̃̃rmas (Har sõõrdmas), sõ̃̃rme, sõ̃r-

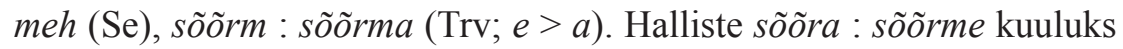
eesti harvade $a$ : me-tuletiste hulka (Länsimäki 1987: 116). Eesti ja liivi keelele on ühine sõormes, kus sisekaolisele genitiivivormile on liitunud $s$-sufiks.

Teise rühma moodustab huokain-sõnapere, mis on eri sufiksitega tuletatud hingamist märkivast verbist, nt sm huoata '(sügavalt) hingata; hinge tõmmata, puhata' (erinevaid sõnakujusid vt SMS 4): sm huokain, huokuin, huokonen, huokunen, huokosin, huokusin; krj huokain, huokon, huokuma, lisaks Valdai huogam(i) ja Tveri huogome, huogomuš, huogoma; lü huog(u), huogain, huogam; is hooku, pl hookumet; vdj hookum, pl -at/õt. 
2.4. Sääremari. Laialdase levilaga on pohje-sõnapere (täpsemalt ALFE II: 366, 368-369). Siingi esineb ohtrasti häälikulist varieerumist ja domineerivad in : ime-tuletised: sm pohje (harilik), pohkea (ka krj), pohkein, pohkijain (ka is), pohkio, pohkio(i)n. Lüüdi keel puudub kaardilt, kuid sõnaraamatus (LMS) leidub siiski üks teade: pl pohkied.

\section{Levilad}

Osa kehaosade nimetusi on levinud laiemal alal, osa käibel vaid ühes läänemeresoome keeles või isegi ühes-kahes murrakus. Tuntumatest nimetustest võiks mainida järgmisi. Pealae nimetus päälaki (e pea/pää+ lagi) on levinud üsna laialt ( $\mathrm{sm}$, lü, vps, is, vdj, e, lv), kuid karjala keeles on selle kohta vaid üksikteateid ja Võru murdes käibib see ainult väljendis pealaest jalatallani (vt ALFE II: 370, 371). Seevastu piirdub oimukohta märkiv ohimo-sõnapere põhiliselt soome keelega, lisaks üksikteated karjala ja vadja keele ning Eesti kirderannikumurde kohta (vt 2.2).

Mitmed laialt levinud sõnad jagavad läänemeresoome keeled kahte lehte. Näiteks ühelt poolt ninasõõret märkiv sierain-sõnapere (sm, krj, vps, vdj, e, lv) ja teiselt poolt huokain-sõnapere (sm, krj, lü, is, vdj; vt ka 2.3). Levilalt vastanduvad sääremarja nimetusedki: pohje-sõnapere (sm, $\mathrm{krj}$, is) ja sääri/marja (ingerisoome, is, vdj), eP sääre / eL seere-, harva eP, eL jala + mari. Vt ALFE II: 364, 368; vt ka 2.4, 6.1.2.

Silmalau nimetust luomi tuntakse vaid soome, karjala ja lüüdi keeles (ALFE II: 384, 386). Ainult karjala keeles käibib pää/lakka 'pealagi' (ALFE II: 370-371; vt ka 6.1.1). Õige vähesed soomlased teavad, et pealae nimetus võib olla kiire (inimesel: VesL, Tot, seal: Hin). Piibli kaudu on levinud väljend kiirestä kantapäähän (ALFE II: 370-371; SMS 7 s. v. kiire'; vt ka 4.3, 5.2).

\section{Semantiline külg}

4.1. Mõned nimetused käibivad üksiksõnana. Nad märgivad üksnes teatud kehaosa ja ei midagi muud, nagu sm ikenet, e igemed (vt 2.1). Sama tüüpi nimetus võib olla eri kehaosadelgi, kui neil on midagi sarnast. Soome ohimo-sõnapere tähenduseks on harilikult 'oimukoht'. Karjala keelest leidub selles tähenduses - ilmselt soome keele vahendusel - vaid mõningaid üksikteateid (vt 2.2), keeleomasem on hoopis ohimo (IloK) / pl ohimet 
'kube(med)'. Sama tähendus on sõnal ka Ida-Soome murretes. Mõlemal juhul on tegemist õhukese kohaga, olgu siis pea juures või alakõhus. Vt Koski 1987: 92-93; ka 5.1.

4.2. Osa nimetusi käibib ka üksiksõnana, sageli on neil küll fakultatiivne täiend, millest selgub kehaosa, nagu sm nenä(n)/sierain või -huokain, e nina/sõõre; sm sääri/sääris + pohje-sõnapere (ALFE II: 364, 368). Teinekord on täiendsõna obligatoorne: 'sääremari' - sm sääri/marja, eP sääre (eL seere)/mari jt (ALFE II: 368 s. v. -marja); 'silmalaug' - sm silmä $(n) /$ silmi + lauta, e silmA/laud, lv siilma/looda (ALFE II: 385, 387). See ilmneb ka selgroo nimetustes, kus täiendsõnaks võivad olla sm selkäl selki, e selg/seljA (eL sälg / säl(l)ä), lv säälga (ALFE II: 374, 376).

4.3. Inimese anatoomia seisukohalt on kehaosad täpselt kindlaks määratud ja teaduslike nimetustega (terminitega) tähistatud. Rahvasuus jäävad nii kehaosade omavahelised piirid kui ka nende nimetused tihti ähmaseks. Kuna oimukoht asub kõrva ja silmakulmu vahealal, on õigustatud nimetus krj, lü korvan/juuri 'oimukoht'. Harilikult märgib see karjala keeles kohta, kus kõrv kinnitub pea külge. Segane on ka pealae ja kukla eraldusjoon, vrd sm kiire 'pealagi' ja eP kiir(e)-sõnapere, lv ki'r 'hinterkopf, scheitel' ('kukal, pealagi') (LW). Vt 5.2. Ühised on mitmed nimetused, mis märgivad pealage ja pehmet luustumata kohta (lõge ehk fontanell) imiku või väikelapse koljul, nagu sm lakuainen, pää/lakka (Ilo); krj peä/lakka Sal (KKS 4), vdj pää/kukkula (VKS 4). Vt ka 6.1.

Silmalau külge kinnituvad ripsmed. Pole siis juhus, et keeliti või murrakuti võivad kokku langeda mõlema nimetused: sm luomi, luoma (harva krj) 'silmalaug', kuid ka sm luomi Iit, Jaal, Kymi 'silmalau sisekülg', Hat 'ripsmete ja kulmukarvade vaheala', luoma Kymi 'silmaripse', Ylän 'silmakoobas'. Sama näeme ka deskriptiivsete sõnade puhul: vps pl ripsud, silma/ripš, $\mathrm{pl}$-ripšud 'silmalaug', kuid rips : ripsun, $\mathrm{pl}$ silma/ripsud 'ripsmed', lisaks räpš : räpšun 'silmalaug', aga räpš/karv'ripsmekarv'; is silmä/ripsu 'silmalaug, -ripse', kuid silmä/räpsü, pl -räpsüt 'silmaripse'; vdj ripsi 'silmalaug, -ripse', silmä/rüpsü 'silmalaug'. Vt ALFE II: 384, 386. 


\section{Oma- ja laensõnad}

Kehaosade nimetuste päritolu puhul tuleb arvestada mitut võimalust, millest allpool.

5.1. Nimetuse algupära (etümoloogia) pole teada, nagu sõna sierain 'ninasõõre' puhul. Mõnikord saab seda vaid oletada. Nii arvab Lauri Hakulinen, et oimukohta või kubet märkiv ohimo-sõnapere on tuletatud oha/ohi-tüvest, tähenduseks 'õhuke koht (peas või alakõhus)', vrd sm ohut 'õhuke'. Algupärasem oleks oha-tüvi. Osmo Nikkilä peab tuletusaluseks ohi-tüve, mille murdeline tähendus on 'äär, serv, külg'. Vt Hakulinen 1956: 198-200; Nikkilä 1992; SSA.

5.2. Kehaosade nimetusi on tihtipeale laenatud. Keelekontaktide kaudu on see mõistepiirkond võrreldes muu leksikaga märksa uuendusmeelsem (vt Haarmann 1983). Laenatud on eri aegadel ja eri keeltest. Mõned laenud võivad olla üsna vanad. Nende hulka kuulub sm kiire 'pealagi', harva 'kukal', mis Jorma Koivulehto (1998) järgi on balti laen - tüvi *škșiria-, vrd It škīre 'juukselahk'. Sama algupära oleks lv ki'r 'kukal, pealagi', samuti Eesti saarte ja läänemurdele iseloomulikud sõnad kiird, kiir : kiiru/kiira, kiire : kiirde/kiire/kiirme 'kukal, kuklatagune'; kohati ka 'mäeküngas, seljandik' (kõik EMS III,11 s. v. kiire ${ }^{2}$ ), kiires 'kukal, kaelatagune; pealagi; mägi, mäeselg' (EMS III,11 s. v. kiires ${ }^{5}$ ), vrd kiirg : kiira Käi, Rei 'otsmikuluu' (EMS III,11 s. v. kiirg' ${ }^{1}$ ). Vt ka 3, 4.3. Laensõnade rohkuselt paistavad silma liitsõnalised selgroo nimetused, nagu sm, krj selkä/ranka, -ranko, sm -ruoko, e selg/roog, -rood. Vt ka 6.5. Hilislaene koguneb võrdlemisi vähe. Suurima levilaga on kaks vene laenu: krj nozra, nozro, lü, vps nozr 'ninasõõre' < vn ноздра; krj, lü, vps, is, vdj viska 'oimukoht' < vn висок, lisaks krj viskaine id., kus laensõnale liitub omasufiks. Teistest on pigem hajateateid: krj pozvonočnikk/a, -о 'selgroog' < vn позвоночник; lü, vps kosic 'oimukoht' < vn косица, lü kosnic id. < vn косница 'naise peaehe' (tähendusmuutus: peaehe seoti üle oimukoha), vt SRNG; ALFE II: 362; lv (idaliivi) plikstiń 'silmalaug' < lt acu plikstiens $\sim$ plikstiņš (ME s. v. I plikstiens); di'nniń, Sal deni 'oimukoht' < lt deniņi, murd diniņi, Dundaga diniš < kasks dünninge (Suhonen 1973: 100), Sal džuokžed 'igemed' < lt žuoklis 'lõualuu' (Suhonen 1973: 105). 
5.3. Oma keeleainesest on moodustatud enamik liitsõnalisi nimetusi, nagu sm silmä $(n) /$ silmi + lauta, e silma/silmA + laud, lv siilma/looda (au >oo) 'silmalaug', vt ka 6.3; eP meele/koht (eL-kotuss; vt ka 6.4).

Etümoloogiad võivad aja jooksul ka muutuda, omasõnaks peetut võidakse tõlgendada hoopis laenuna. Nii on juhtunud igemeid märkiva sõnaga (sm ikenet, e igemed jt). Selle soomeugrilise päritolu on vaidlustanud Tiit-Rein Viitso (1993) ja oletanud indoeuroopa laenu. Nasaalide $n / m$ vaheldus (vt 2.1) pärineks siis laenu andnud keelest.

\section{Nimeandmismotiivid}

Nime andmist mõjutavad mitmesugused keelevälised seigad. Tavalisem on see, et nimi antakse selle järgi, mida nähakse, olgu siis väliskuju (sarnasus millegagi) või asukoht. Alles seejärel tuleb kehaosa funktsioon (vt Koski 1987: 37) või midagi muud.

6.1. Väliskuju domineerib paljudes nimetustes. Veidi nõgusat oimukohta, mis tundub tühja ja õõnsana, saab eesti murdekeeles kirjeldada nii: Lüg, Jõh tühi kõht, Jõh tühimuse kõht $(o>\tilde{o})$. Soomes on see onnen/kohta (onsi : onnen 'õõnsus, õõs'; ALFE II: 360, 362; vt ka Koski 1992: 140-141). Ninal on kaks avaust, mille kaudu inimene hingab, haistab jne. Kirjeldavates nimetustes ongi liitsõnade põhisõnaks auku (lõhet) märkivad sõnad: sm -laukku, -läpi, -reikä, Värmlandis rootsi laen -holi< hål 'auk'; sm (harva), vdj, eP -auk, eL -mulk, krj -loukko (ALFE II: 380, 382). Põhisõnadest lähemalt ALFE III: 438-439.

6.1.1. Inimese pealae kuju pakub hulga võimalusi (ALFE II: 370-371). Pealae ülaosa on keha kõrgeim punkt ja meenutab tasast kõrgendikku, mis tõuseb ühtlaselt igast küljest. Seetõttu on omal kohal võrdlus kingu või mäega: sm pää + kukkula 'kink; kõrgendik; kõrgustik; tipp', ilma täiendsõnata is kukkul, vdj kukkula. Sünonüümne sm kukkura esineb liitsõnas pää(n)/kukkura. Lõuna-Pohjanmaal märgib see ka mingi aine kuhja (kuhjakest), mis on nõus kerkinud keskelt kõrgemale kui ääred. Kõrgema koha (tipu) tähendus tuleb esile nimetustes krj pää/lakka (lakka 'tipp, hari, lagi, latv'; nagu teistes läänemeresoome keelteski 'pööning, lakk'); sm lakil pää, e lagi + pea/pää (põhisõna märgib pealmist osa, tippu, harja vms). Nimetustes esineb laki veel liitsõnades: sm, krj (harva), lü, vps, is, vdj, e, lv pä̈̈/laki; eL lagi/paik. Enamasti tähendab see sõna kõrgemat kohta, 
tippu vms, nt vadja, eesti ja karjala keeles (KKS 3) hoone lage (praegusel juhul oleks see pead ülalt- või altpoolt piirav pind).

6.1.2. Väga kõnekad on motiivid, miks sääremarja nimetatakse just nii (vt ALFE II: 367, 369). Kuna lihaseline sääremari on väliselt paksuvõitu ja kumer, vastandub ta sääre luisele esiosale ja meenutab inimese ümarikku kõhtu ehk nagu soomlane ütleb: selkä edessä, vatsa takana 'selg ees, kõht taga'. Mitmes liitsõnalises nimetuses ongi põhisõnaks mingi kõhtu märkiv sõna (neist lähemalt Koski 1992: 153-154, 161): sm sääri/ säären-, jalan/jalka + vatsa, kinttu- 'jalg, kints', sääri/maha; krj jalgal pöččöne; eP (Hää) jala/kõht.

Põhisõnaks võib olla ka marja: sm (harva), is, vdj sääri/marja, eP sääre / eL seere + mari, harva eP, eL jala/mari. Nimetuse tuumalaks näib olevat Eesti, kust see on levinud ingerisoome, isuri ja vadja murretesse. Eksisteerib kaks võimalust: põhisõna märgib taime pehmet ja lihakat vilja või kalamarja. Järgmiste nimetuste puhul aga kahtlust pole: krj ikra; eL pl jala/ikrõ Lei; lv (jaalga)muuma. Kuna sõnadel ikra ja muuma on kaks tähendust - 'sääremari' ja 'kalamari' -, tuleb selguse mõttes lisada täiendsõna. Karjala keeles on tegemist vene laenuga (vn икра 'sääre-, kalamari'), leivu keeles tõenäoliselt läti omaga (lt ikri id.). Sääremari meenutab väliselt marja täis emaskala, mistõttu langevadki mitmes soomeugri ja indoeuroopa keeles kokku sääremarja ja kalamarja nimetused (vt Sadovszky 1975).

Sääremari võib näida ka mingi mütsaka või kamakana: krjjalga/möwkküne (vrd sm möykky 'kamakas, tomp; kühm, mügar'), pahko ( $a>o$; pahka 'puupahk; muhk, kühm'). Esile saab tõsta ka (näilist) pehmust (krj pehmie kohušta 'pehme koht') või olulisust (eP sääre + tuum/tumm 'tuum').

6.2. Asukoht. Kuna oimukoht asub nurkmisel alal - otsmiku, silmakulmu ja kõrva vahel, on igati õigustatud nimetused sm, krj, lü kulma (sm 'nurk; silmakulm', krj, lü 'silmakulm'); sm otsa/otsi 'otsmik' + kulma (ALFE II: 358,361$)$.

6.3. Funktsioon. Silmalaug peab silma katma, peitma ja kaitsma. See ülesanne ilmneb ka nimetustes sm kansi 'kaas', silmä(n)/kansi; vdj silmä( $\ddot{a}) /$ kaasi, silmä/katto 'katus; kaas', ka silmää katõ 'kate, vari'. Sama motiiv tuleb esile liitsõnades, nagu sm silmä(n)/silmi + lauta 'laud', e silmA/ laud, lv siilma/looda $(a u>o o)$. Inimese silmalaul on sama otstarve kui 
lauakesel, mis seoti lehma või härja silmade ette, et takistada teda üle aia hüppamast ja väravaid avamast. Vt ALFE II: 384-387.

6.4. Rahvapärased uskumused. Eestis on oimukoht seotud ennekõike taju(mise), mõistuse ja mõtlemisega: eP meele + koht (eL -kotuss 'koht'), mõistuse-, mõtte-, oimu/koht (kohati oim : oimu 'mõistus, aru, taip'; sõna etümoloogia pole täiesti selge, vt SSA; ALFE II: 361). Argielus osutatakse sageli sõrmega oimukohale, kui peetakse teist inimest või tema teguviisi väga rumalaks. Kuna mõtlemine on omakorda seotud peaajuga, siis mõnikord sisaldab seda sõna ka oimukoha nimetus: eP aiu/koht, aiude koht.

Samal ajal on oimukoht küllalt õrn, sest kolju on siin õhuke ja seda saab kergesti vigastada (Koski 1987: 93). Ega asjata ei nimeta rahvasuu oimukohta sõnaga eP elukoht Kuu, Kad. VtALFE II: 360, 362. Enesetapjad suruvad relva tihti oimukohale.

6.5. Selgroo (lülisamba) liitsõnalistes nimetustes esinevad mitmesugused motiivid (ALFE II: 373-376), kuid alati on obligatoorne täiendsõna, mis näitab asukohta - selga. Inimese kehas on palju luid, olulisim on vaid üks: sm, krj, is, vdj selkä-, eP seljA-, eL sellä/sälä + luu; eP seljA/ kont. Soome keeles võib selkä/luu olla ka üksainus selgroolüli. Püstine selgroog on keha kandvaim tugiosa. Seda saab võrrelda teiba või ridvaga, samuti puutüve või taimevarrega: sm, krj selkä/ranka, -ranko. Põhisõna tähendab langetatud või laasitud peenikest puutüve. Võimalikud on kolm laenuetümoloogiat: a) rootsi keel, vrd vanarootsi rang 'kanaõrs', nüüdisrootsi murdeline rång 'lõhestamata aiaroigas, pooleks saetud ja laasitud pikk ja peenike puutüvi'; b) skandinaavia algkeel: *strangā, vrd nüüdisnorra strang(e) 'peenikese puu laasitud tüvi'; c) balti keeled, vrd ld dránga 'jäme teivas, latt, ritv' (SSA). Siia rühma kuuluvad sm, krj, lü, vps, is, vdj, eP selkä/ruoto. Põhisõna on germaani laen: *rōđa-, rōđōn, vrd nüüdisrootsi rod 'aiateivas', nüüdissaksa Rute 'vits, latt' (SSA). Läänemeresoome keeltes märgib ruoto/rood kandvat tugi- või kinnitusosa (nt lehe-, kala-, sulerood). Eesti keeles on võinud seguneda ka $g$ ja $d$ (roog ja rood) (Kettunen 1929: 34-35). Lõunaeesti murretes (Lut) on tegemist vene laenuga sel'a/sośt (< vn wecm, murdeline wocm 'teivas, ritv, latt'; vt Vasmer 1973).

Selgroog koosneb kõhrelistest või luustunud lülidest, mille ogajätked meenutavad veidi hammast: sm, krj, lü selkä/pii. Läänemeresoome keeltes 
märgib põhisõna hammast, kohati rehapulka või kammipiid. Seega võib öelda, et selgroo nimetuses esineb pars pro toto.

Lülide vahele moodustub püstkanal, milles asub seljaaju. Kanalit saab võrrelda mingi toruja, seest õõnsa objektiga (nt veetoru, taime vars): eP selg/roog 'taime õõnes vars; kõrkjas', seljA/toru, -putk 'taime torujas vars, eseme torujas osa'.

\section{Kokkuvõtteks}

Kõigis läänemeresoome keeltes, kui välistada teatavad häälikulised erinevused, on pea, nina, jala(sääre) ja selja nimetused samasugused. Nende osi (igemed, oimukoht, silmalaug, ninasõõre, sääremari, selgroog) nimetatakse keeliti või murrakuti enamasti isemoodi. Selleks on mitu põhjust. Osa nimetusi on laenatud eri aegadel ise suunast. Vanemad neist on germaani (resp. skandinaavia algkeele või rootsi) või balti laenud, hilisemad pärinevad vene või läti keelest. Nimetustes kajastuvad ka keelesisesed eriarengud, nagu häälikumuutused, in : ime-tuletiste segunemine teist tüüpi (eriti $m: m a-$ ) tuletistega jm. Seetõttu on sama algupäraga sõnad võinud praeguseks oluliselt lahkneda, vrd sm sierain, sieraim jt ja e sõ̃re jt 'ninasõõre' (vt 2.3). Ühe või teise kehaosaga seostub erinevaid kujutluspilte, kui võrrelda seda mõne muu objektiga kas väliskuju, asukoha, funktsiooni või muu tunnuse järgi (vt 6).

\section{Lühendid ${ }^{2}$}

Hat $=$ Hattula ; Hin $=$ Hinnerjoki; $i d .=$ idem 'seesama'; Iit = Iitti; Ilo = Ilomantsi $(\mathrm{sm})$; IloK = Ilomantsi $(\mathrm{krj})$; Jaal = Jaala; Kymi = Kymi; lü = lüüdi keel; Sal = Salatsi (lv); Salmi (krj); s. v. = sub voce 'mainitud sõna all'; Tot = Tottijärvi; VesL $=$ Vesilahti; Ylän $=$ Yläne

\section{Kirjandus}

ALFE = Atlas Linguarum Fennicarum. Itämerensuomalainen kielikartasto. Läänemeresoome keeleatlas. Ostseefinnischer Sprachatlas. Лингвистический атлас прибалтийско-финских языков. II, 2007 (= Suomalaisen Kirjallisuuden Seuran Toimituksia 800. Kotimaisten kielten tutkimuskeskuksen

2 Siin on esitatud vaid need lühendid, mis aastaraamatu lühendiloetelust puuduvad. 
julkaisuja 118.); III, 2010 (= Suomalaisen Kirjallisuuden Seuran Toimituksia 1295. Kotimaisten kielten tutkimuskeskuksen julkaisuja 159.) Helsinki: Suomalaisen Kirjallisuuden Seura, Kotimaisten kielten tutkimuskeskus.

EEW = Mägiste, Julius 1982-1983. Estnisches etymologisches Wörterbuch. I-XII. Helsinki: Finnisch-Ugrische Gesellschaft.

EMS = Eesti murrete sõnaraamat. III, 11 (ket-kiriklik), 2001. Toim. Anu Haak, Evi Juhkam, Varje Lonn, Helmi Neetar, Piret Norvik, Vilja Oja, Jüri Viikberg. Eesti Teaduste Akadeemia, Eesti Keele Instituut. Tallinn: Eesti Keele Instituut.

Haarmann, Harald 1983. Zur Problematik lexikalischer Entlehnungen im Bereich der Körperteilbezeichnungen. - Finnisch-Ugrische Forschungen XLV (1-3). Helsinki, 127-151.

Hahmo, Sirkka-Liisa 1994. Grundlexem oder Ableitung. Die finnischen Nomina der Typen kämmen und pähkinä und ihre Geschichte. (= Studia Fennica Linguistica 5.) Helsinki: Suomalaisen Kirjallisuuden Seura.

Hakulinen, Lauri 1956. Über das finnische Wort ohimo und seine Verwandten.Ural-Altaische Jahrbücher XXVIII. Wiesbaden: Otto Harrassowitz, 196-200.

Kettunen Lauri 1929. Eestin kielen äännehistoria. Toinen, uusittu painos. (= Suomen Kirjallisuuden Seuran Toimituksia 156.) Helsinki: Suomalaisen Kirjallisuuden Seura.

KKS = Karjalan kielen sanakirja. 3 (L-N), 1983. Päätoim. Pertti Virtaranta. (= Lexica Societatis Fenno-Ugricae XVI, 3.); 4 (O-P), 1993. Päätoim. Raija Koponen. Toim. Leena Joki, Katariina Jeskanen. (= Lexica Societatis Fenno-Ugricae XVI, 4. Kotimaisten kielten tutkimuskeskuksen julkaisuja 25.) Helsinki: Suomalais-Ugrilainen Seura, Kotimaisten kielten tutkimuskeskus.

Koivulehto, Jorma 1998. Kiire 'päälaki' ja muuta etymologista rajankäyntiä. - Oekeeta asijoo. Commentationes Fenno-Ugricae in honorem Seppo Suhonen sexagenarii 16. V 1998. Toim. Riho Grünthal, Johanna Laakso. (= Suomalais-Ugrilaisen Seuran Toimituksia 228.) Helsinki: SuomalaisUgrilainen Seura, 360-367.

Koski, Mauno 1987. Ihmisen ruuminosien nimitykset suomessa ja ruotsissa (1). - Kontrastiivista kielentutkimusta I. Toim. Mauno Koski. (= Fennistica 8.) Turku: Åbo Akademi, 25-116.

Koski, Mauno 1992. Ihmisen ruuminosien nimitykset suomessa ja ruotsissa (2). - Kontrastiivista kielentutkimusta II. Toim. Mauno Koski. (= Fennistica 10.) Turku: Åbo Akademi, 135-169.

LMS = Lyydiläismurteiden sanakirja. 1944. Toim. Juho Kujola. (= Lexica Societatis Fenno-Ugricae IX.) Helsinki: Suomalais-Ugrilainen Seura. 
LW = Lauri Kettunen 1938. Livisches wörterbuch mit grammatischer einleitung. (= Lexica Societatis Fenno-Ugricae V.) Helsinki: Suomalais-Ugrilainen Seura.

Länsimäki, Maija 1987. Suomen verbikantaiset in: ime-johdokset. (= Suomalaisen Kirjallisuuden Seuran Toimituksia 469.) Helsinki: Suomalaisen Kirjallisuuden Seura.

ME = Karlis Mülenbacha 1923-1932. Latviešu valodas vārdnīca. I-IV. Redigèjis, papildinājis, turpinājis Jānis Endzelīns. Rīgā: Izdevusi Izglīitības ministrija.

Nikkilä, Osmo 1992. Omasta takaa. Kahden suomen sanan alkuperästä. - RédeiFestschrift. Festschrift für Károly Rédei zum 60. Geburtstag. Emlékkönyv Rédei Károly 60. születésnapjára. Hrsg. Pál Deréky, Timothy Riese, Marianne Sz. Bakró-Nagy, Péter Hajdú. (= Studia Uralica 6, Urálisztikai tanulmányok 3, Linguistica. Series A. Studia et Dissertationes 8.) WienBudapest, 361-365.

Sadovszky, Otto J. 1975. The Concepts of the 'calf of the leg' and 'fish eggs' and the Tattooed Man of Pazyryk 2. - Congressus Tertius Internationalis Fenno-Ugristarum Tallinnae habitus 17.-23. VIII 1970. Pars I. Acta Linguistica. Redegit Valmen Hallap. Adiuvantibus Anu-Reet Hausenberg, Aime Kährik. Tallinn: Valgus, 149-154.

SKES = Suomen kielen etymologinen sanakirja. 1955-1981. (= Tutkimuslaitoksen Suomen suvun julkaisuja III. Lexica Societatis Fenno-Ugricae XII.) Helsinki: Suomalais-Ugrilainen Seura.

SMS $=$ Suomen murteiden sanakirja. 4 (huka-iätös), 1994. Päätoim. Tuomo Tuomi; 7 (kiainen-konkelopuu), 2003. Päätoim. Matti Vilppula. (= Kotimaisten kielten tutkimuskeskuksen julkaisuja 36.) Helsinki: Painatuskeskus / Kotimaisten kielten tutkimuskeskus, Suomalaisen Kirjallisuuden Seura.

SNRG = Словарь русских народных говоров. 1965-. Москва, Ленинград / Санкт-Петербург: Академия наук СССР, Институт русского языка / Российская академия наук, Институт лингвистических исследований.

SSA = Suomen sanojen alkuperä: Etymologinen sanakirja. 1 (A-K), 1992. Päätoim. Erkki Itkonen; 2 (L-P), 1995; 3 (R-Ö), 2000. Päätoim. Ulla-Maija Kulonen. (= Suomalaisen Kirjallisuuden Seuran Toimituksia 556. Kotimaisten kielten tutkimuskeskuksen julkaisuja 62.) Helsinki: Suomalaisen Kirjallisuuden Seura, Kotimaisten kielten tutkimuskeskus.

Suhonen, Seppo 1973. Die jungen lettischen Lehnwörter im Livischen. (= Suomalais-Ugrilaisen Seuran Toimituksia 154.) Helsinki: SuomalaisUgrilainen Seura.

Vasmer = Макс Фасмер 1973. Этимологический словарь русского языка. Т. 4. Перевод с немецкого и дополнения О. Н. Трубачева. Москва: Прогресс. 
Viitso, Tiit-Rein 1993. Livonian i'gmõd 'gums'. - Linguistica Uralica XXIX, 173-175.

VKS = Vadja keele sõnaraamat. Словарь водского языка. 3 (L- müüäG), 1996; 4 (N-P), 2000. Toim. Elna Adler, Merle Leppik. Eesti Teaduste Akadeemia, Eesti Keele Instituut. Tallinn: Eesti Keele Instituut / Eesti Keele Sihtasutus.

Helmi Neetar

ESi auliige

J. Sütiste tee $34-72$

13411 Tallinn

helmi.neetar@gmail.com 


\title{
Names of body parts in the Atlas of Finnic Languages
}

\author{
Helmi Neetar
}

The three parts of the Atlas Linguarum Fennicarum (ALFE) were published in the years 2004-2010. Part 2 addresses, among other things, a group of concepts associated with human anatomy (gums, nostril, calf, temple, crown, eyelid, spine). Their Finnic references can be analysed from different aspects.

Some of the names display considerable phonetic and derivational variation, e.g. Fin. ikenet etc., North-Est. igemed, idemed, South-Est. igimä', igima 'gums'; Fin. ohimo etc., 'temple'. There are numerous compounds, most of which have an obligatory attributive component: Fin. $\operatorname{silmä}(n)$ 'eye' + kansi 'eyelid'.

Some names are rather widespread, such as the following two word families for nostril: *seerV- (Fin. sierain, Est. sõorre; also Veps., Vot., Liv.) and East-Fin. huokoin < huoata 'breathe (deeply); rest' (also Kar. Ingr., Vot.). Some others are used in a very small area.

There are names that are strictly limited to certain body parts, e.g. Fin. ikenet, North-Est. igemed 'gums'. Some names derive from native linguistic material. For example, the Finnish word family ohimo etc. has been associated with the adjective oha/ohut etc. 'thin', as the human skull is thin at temples. At the same time there are several loanwords, which can be very old or rather recent (Russian, Latvian) borrowings.

The naming motives are more associated with visual aspects: (a) external form - the hollowness of the temples has probably motivated the North-Est. tühi 'hollow / empty' $+k \tilde{o} h t(o>\tilde{o})$ 'place', Fin. onnen (onsi : onnen) 'hollow' + kohta 'place'. A round-shaped muscular calf may be associated either with the roundness of the belly (Fin. sääri 'leg' + vatsa 'belly', Est. jala (Gen.) 'leg' + kõht 'belly'), berry, or roe (North-Est. sääre / South-Est. seere (Gen.) 'leg' + mari 'berry; roe'; also Vot., Ingr.); (b) location - here belong such designations of the temples as the Fin., Kar. kulma ('corner') and Fin. otsa / otsi 'forehead' + kulma. The high position of the crown could have yielded the Fin. pää 'head' + kukkula 'hill, top'. The function is very imporant. Several terms for the spine combine references to the erect position and the support function. The most important function of the eyelid is that of protecting the eye, as proved by the Fin. silmä(n) 'eye' + kansi 'lid', Vot. silmä + katto 'roof; lid'. Estonian terms reveal the belief that temples have to do with reason and thinking: meele (Gen.) 'mind; perception; reason' + koht (South-Est. kotuss) 'place'.

Keywords: phonetic and derivational variation, areal distribution, semantic aspect, native words, loanwords, naming motives 